\title{
Reconsidering deconstruction in information systems research
}

\section{Mike Chiasson ${ }^{1}$ and Elizabeth Davidson ${ }^{2}$}

${ }^{1}$ Department of Management Science, Lancaster University, Lancaster, U.K.; ${ }^{2}$ Department of Information Technology Management, Shidler College of Business, University of Hawaii at Manoa, Honolulu, U.S.A.

Correspondence: Elizabeth Davidson, Department of Information Technology Management, Shidler College of Business, University of Hawaii at Manoa, 2404 Maile Way, Honolulu, HI 96822, U.S.A.

Tel: + 1 (808) 956 6657;

Fax: + 1 (808) 956 9889;

E-mail: edavidso@hawaii.edu
Received: 7 February 2010

Revised: 7 September 2011

Accepted: 17 October 2011

\begin{abstract}
Deconstruction, a post-structuralist approach to examining language in texts, is most often associated with the philosophical works of Jacque Derrida. After a flurry of interest among management and information systems (IS) scholars, this qualitative approach to exploring organizational texts has received little attention in the IS literature. We suggest deconstruction could help our field explore how IS texts describe the social and technical past and also prescribe and circumscribe the future of IS practice. Thus, we suggest the IS field reconsider how deconstruction might contribute to language-based approaches in IS research and practice. In this paper, we discuss deconstruction in light of the linguistic turn in social science research and the support and criticism for its use in management research. We consider IS research publications that have employed deconstruction explicitly, examine a wellknown IS publication as an example of the deconstruction of IS texts, and suggest ways in which deconstruction might be applied to various genres of IS texts to inspire insights and creativity. To conclude, we highlight considerations for researchers who might adopt this approach and for the editors and reviewers who would evaluate qualitative research papers that employ deconstruction.

European Journal of Information Systems (2012) 21, 192-206. doi: 10. 1057/ejis.201 I.55; published online 15 November 201 I
\end{abstract}

Keywords: deconstruction; post-structuralism; discourse analysis; information systems practice; qualitative methods

We are written, only as we write ... Jacques Derrida, Writing and Différance

\section{Introduction and motivation}

Information systems (IS) - as designed socio-technical artifacts and as objects of study - are inexorably entwined with language. We use language to describe the IS we build, to explain and justify their possible uses and implications, and to represent the data and information they contain for use in various settings and for various purposes. As researchers we draw from and extend language in order to study IS phenomena. Although language is clearly important to such activities in the IS field, as practitioners and as researchers, we often do not consider explicitly the performative implications of language or the ways in which language per se may contribute to persistent problems, such as the design of systems that fail to meet the needs or serve the interests of their intended users (Hirschheim et al, 1996).

In this essay, we consider a language-based approach to analyzing the many types of texts found in IS-related activities, which we believe holds promise for the IS field. Deconstruction is a post-structuralist approach to analyzing language in texts and is most often associated with the work of Jacques Derrida $(1978,1982,1985,2002)$. Deconstruction has been applied 
in literary criticism and had a small following in the organizational and IS literatures in the 1980s and 1990s (Cooper, 1989; Weitzner, 2007). This early work resulted in some notable publications in those fields (cf., Calás \& Smircich, 1991; Martin, 1990a; Kilduff, 1993; Beath \& Orlikowski, 1994; Chia, 1994). Deconstruction has some similarities to other language-based approaches found in IS research, such as hermeneutics (cf. Lee, 1994), discourse analysis (cf. Swanson \& Ramiller, 1997; Heracleous \& Barrett, 2001), and conversation analysis (cf. Urquhart, 1999, 2001). However, we suggest deconstruction offers unique and complementary possibilities for language-based study.

In response to the EJIS special issue call for philosophical essays and appraisals of a wide range of qualitative research approaches, we suggest the IS research field reconsider how this language-based approach to examining IS texts might contribute creative and innovative insights on the nature of IS, on pervasive issues with their development and use, and on the task of IS research itself. Our goals in this essay are to familiarize researchers with deconstruction as a philosophical and methodological research approach, to highlight how deconstruction might be used in qualitative IS research focused on language, and to suggest some practical implications and steps for researchers intrigued by its possible applications.

To do so, we first discuss deconstruction as a poststructuralist approach to language in discourse and consider supporters' claims and detractors' critiques. We consider the philosophical assumptions of deconstruction and draw contrasts with structuralism, post-structuralism, and critical theory. We review how deconstruction has been employed in IS research publications and examine in detail a publication by Beath \& Orlikowski (1994), in which the authors deconstruct the portrayal of user-developer dichotomies in a systems development methodology. Drawing on this retrospective appraisal of deconstruction in the IS field, we suggest possible applications of deconstruction that could contribute new insights on topics of long-standing concern to the IS field, such as technology innovation, the social implications of technologies, and research relevance. As we consider whether this unconventional approach is practical in IS research, we highlight possible reasons why deconstruction has found limited use in IS research and suggest strategies to overcome barriers to more extensive use. Consistent with the special issue call, this essay is aimed at qualitative researchers interested in the possibilities and challenges of language-based research in IS research and for editors and reviewers who might evaluate research papers adopting deconstruction.

\section{Deconstruction as philosophy}

The term 'linguistic turn' refers to broad changes in philosophy and social science toward the study of language and interest in how language constructs and produces our subjective and inter-subjective worlds (Crotty, 1998; Alvesson \& Karreman, 2000; Heracleous,
2006). Language-based research investigates how humans construct and act in the world through language, by examining the linguistic world of participants (Phillips \& Hardy, 2002; Fairclough, 2003). Although linguistic philosophies share a focus on language as the foundation of social life and meaning, they address basic questions about language quite differently: What is our purpose in studying language? What is the role of language in constructing our world? How and what do we analyze about language? What is the role of social scientists in the research endeavor? To appreciate ways in which deconstruction might contribute to language-based IS research; we first consider how deconstruction relates to structuralism and post-structuralism, two schools of linguistic philosophy. For in-depth discussion of deconstruction's philosophical roots, see Crotty (1998), Deutscher (2005), Milner (1991), and Norris (1991, 2000).

Linguistic structuralism was a radical approach to social science for its time, because it assumed the world is produced by the relationships among words, and not simply that words imperfectly correspond to an external world (Milner, 1991). In the realist position of structuralism, the purpose of the study of language is to uncover the underlying relationships among words, to develop general rules behind the production of language, and to understand structures within language (Harland, 1987; Milner, 1991). These structures are assumed to be inherent in language and to exist independently of the words or 'signals' expressed by individuals. Instead, linguistic structures exist as systems of meaning to which humans conform, independently of human experience, context or history (Milner, 1991). The search for the underlying structures among words is important in structuralism, because the reality embedded in language allows the researcher to claim scientific validity and neutrality (Crotty, 1998; Prasad, 2005).

Post-structuralism was in turn a radical departure from structuralism (Crotty, 1998). Abandoning the positivist aspects of structuralism, post-structuralist linguist approaches cast suspicion on the stability, function, and universal pragmatics of language by questioning its naturalness (Harland, 1987; Milner, 1991). Poststructuralists instead consider language to be unstable, though rendered temporarily stable by social and political forces . Foucault's studies of discourses of insanity, crime, and human sexuality (Foucault, 1990, 1995) are prominent examples of post-structuralism (Crotty, 1998); Foucault's work on genealogy questions how the naturalness of language and discourse is in fact produced from accidents and fractures in history. In Foucault's view, the 'truth' of language is not a natural but a political accomplishment, which renders and mediates power as knowledge.

Deconstruction is a radically interpretive approach to the study of language (Jones, 2003) and is considered to be post-structuralist (Agger, 1991; Crotty, 1998). Derrida's deconstruction assumes that words and concepts have meaning only in relation to other words and concepts 
(similar to structuralism). A concept (signified by a word) can only be understood in contrast to other concepts (e.g., new/old, light/dark, and good/evil), which in turn takes on meaning in relation to yet other concepts. However, the oppositional pairs or binaries assumed to be real in structuralism are destabilized in deconstruction by accentuating the contradictions inherent in a text and seeking to present alternative arrangements and meanings between oppositional pair (Cooper, 1989). Derrida invoked the term différance to imply both the 'differed' and 'deferred' of the oppositional concepts in texts, one concept brought to the foreground as the dominant meaning, with the other pushed to the background and its meaning postponed (Derrida, 1982). Any text or mark is supplemented by techniques and references to other supplementary concepts or marks that themselves point to other supplements. The supplement is separate from but also intrinsic to the dominant concept: it differs, but its meaning is only deferred, not eliminated.

For Derrida, différance is inherent in writing, a requirement to produce meaning (Deutscher, 2005). The terms differance and supplement imply that words and concepts within the text vacillate between the dominant interpretation and its supplement, and their meanings are necessarily undecidable (Cooper, 1989; Deutscher, 2005). Identifying binaries (oppositional pairs) and challenging their apparent naturalness produces a critical overturning:

\footnotetext{
... we are not dealing with the peaceful co-existence of a vis-à-vis, but rather a violent hierarchy. One of the two terms governs the other (axiologically, logically, etc.) or has the upper hand. To deconstruct the opposition is, first of all, at a given moment, to overturn the hierarchy. (Cooper, 1989, p. 483 quoting Derrida, 1981, p. 41)
}

By overturning taken-for-granted interpretations, deconstruction emancipates writers and readers from the constraints of dominant interpretations, while being wary of new and dominating positions.

In these ways, Derrida shifted attention from an enduring structure of language in structuralism to the ongoing process through which meaning must be imposed (and resisted) through language. Agger (1991) comments on the contested and shifting meaning of a text deconstruction thus implies:

Every text is a contested terrain in the sense that what it appears to 'say' on the surface cannot be understood without reference to the concealments and contextualizations of meaning going on simultaneously to mark the text's significance (i.e., the use of specialized jargon). These concealments and contextualizations might be viewed as the assumptions that every text makes in presuming that it will be understood. But these assumptions are suppressed, and thus the reader's attention is diverted from them. (Agger, 1991, p. 112)

An implication of deconstruction is that texts can never have a final and natural meaning, even in the author's mind and hands (Royle, 2003). For the reader (and writer) a text and its effects are never settled but always open to new interpretations and possibilities.

Indeed, deconstruction assumes that every text requires a constant questioning of assumed truths, so as to keep language constantly in play (Cooper, 1989; Jones, 2003; Deutscher, 2005). The term logocentrism refers to the domination of one system of meaning within a text. Logocentrism is resisted through deconstructive 'play' in order to bring to the surface alternative, hidden meanings that are present but suppressed. What results from deconstructive play may be a new perspective, a realization that an apparently hierarchical relationship among dominant and suppressed concepts is constructed, not natural (Jones, 2003, p. 4). Its broadest objective is to bring into account in the sharpest detail, the limitless context referred to in the moment a text is understood, through re-contextualization, with 'an eye sharply trained to look for contradictions' (Norris, 1991, p. 137, quoted in Beath \& Orlikowski, 1994, p. 352).

\section{Deconstruction and critical theory}

Various linguistic philosophies characteristic of the linguistic turn might be termed interpretive or critical, with the first appreciating how language constructs and is constructed by individuals, and the second addressing how power and domination are mediated through language. Deconstruction begins with the assumption that all texts construct meaning by suppressing other possible interpretations; thus it shares an appreciation of social construction through language found in interpretive approaches of discourse analysis. Deconstruction allows for the dominating possibilities of language found in critical discourse analysis (Phillips \& Hardy, 2002; Fairclough, 2003). However, despite its use as a critical method (Jones, 2003) Derrida's post-structuralist philosophy differs from other critical approaches to the study of language.

Critical theory approaches to the study of language, particularly those related to the Frankfurt school, assume that communication can be eventually free of class distinctions and distortion, given proper analytic attention (Feenberg, 2002). The more structural forms of critical theory invoke an ideal of constant vigilance to realize ideal language use free from such distortion (Feenberg, 2002). For example, neo-Marxist approaches to language focus theoretic attention on class conflict and power as the source of distortion in communication (Willis \& Chiasson, 2007). In the works of Habermas, which has some following among IS researchers (cf. Lyytinen \& Hirschheim, 1988; Hirschheim \& Klein, 1994; Ngwenyama \& Lee, 1997), an 'ideal speech situation' free of distortion is possible where people can raise legitimate issues and question claims of relevance. Relative to these forms of critical theory, deconstruction posits that power relations are always present in any text, even in assertions about the central causes of distortion, which may serve as future sources of distortion. 
Jones (2003, pp. 52-53) suggests that while deconstruction and traditional critique may work together, they are not synonymous:

For Derrida, this experience of undecidability is not the onset of passive nihilism and the end of politics, as it is sometimes perceived to be, but is the condition of possibility of a democratic politics worthy of the name ... Caught between two irreducible demands, there is nothing to decide for us. This is the kind of situation, which Derrida has written about from his earliest work. This effort to think through double-binds, of competing demands when there is nothing to tell us which way to go, is particularly distinctive about deconstruction.

Thus, we suggest that the critique of language in deconstruction is strangely more subtle and devastating yet possibly more optimistic than critical theoretical approaches.

\section{Deconstructive analyses}

Deconstruction shares to an extent the ontological and epistemological principles that Milner (1991, pp. 65-66, quoted in Crotty, 1998, p. 198) attributes to structuralism and post-structuralism: anti-humanism (there is little human agency in terms of transforming discourse or structures), anti-historicism (structures exist in the 'theoretical present', thus transcending historical moments), theoricism (concepts and analysis are abstract and formal, rather than grounded in empiricism), and demystification of experiential reality (an emphasis is on new ways of understanding the world, somewhat divorced from human experience of the world). For instance, deconstruction is less concerned with the world 'out there' than it is with the linguistic world within a text:

The deconstructionists, like discourse analysts, look at the details of a text, but unlike discourse analysts, they tend to bracket its social effects. They favor playfulness and imagination over rigor and empirical details. (Alvesson \& Karreman, 2000, p. 143)

However, in various ways, deconstructive analysis may move beyond this characterization. Derrida's notion of 'play' (as playfulness, looseness or slack, participation, and performance) implies human agency in the active engagement of readers and writers with text. That is, deconstruction entails the reader's active involvement with the text to seek out the contradictions. Agger (1991, p. 113) comments,

For Derrida, deconstructive reading pries open inevitable, unavoidable gaps of meaning that readers fill with their own interpolative sense. In this way, reading is a strong activity, not merely passive reflection of an objective text with singular meaning.

If speech and writing are performative (promises of something to come through action) as much as declarative (descriptive) (Royle, 2003, p. 110), then language acts as much as it declares an objective external world and the unstable relationship between the two can be a focus of analysis and of action (Royle, 2003, pp. 27-28). Adopting this positive perspective, Alvesson \& Karreman (2000) categorize deconstruction as a type of 'grounded fictionalism' and suggest that deconstructive inquiry grounded in a close inspection of language, with an appreciation of its multiple meanings and possible interpretations, can enable researchers to bring insight to a specific situation and to extend these insights to a broader social context. If the deconstruction of a text (and subsequent readings of such texts by active readers) result in new ways of comprehending the world, insights may extend beyond the text to the historical and social context, as Kilduff (1993, p. 15) argues:

By questioning the organizing principles of canonical texts, Derrida aims to place these principles in a new relation to each other, suggesting the possibilities that complications can be debated rather than suppressed ... The implications of a deconstructive reading are, therefore, not limited to the language of the text itself but can be extended to the political and social context in which the text is placed.

Consider as an example how an analysis using deconstruction might approach the différance of 'new' and the supplement of 'old' in technology innovation. As authors or readers of innovation texts, we impose the dominant interpretation of technological innovation as new, relying on an understanding of the old in order to make sense of what has changed. New technologies not only differ and supplant the old ones, but they at the same time build on these older technologies through additions or rearrangements; in deconstructive terms, the old is a supplement to the new. The old technology also defers to the new by being hidden and suppressed by the new terminology, new interfaces, and new user practices. Yet, old technologies are renewed through these rearrangements, and new technologies exhibit the limitations and affordances of the old. In Derrida's terms, whether a technology is new or old is undecidable - it vacillates between these oppositional poles in our texts and in our practices.

If we overturn the differance of new to the supplement of old, insights on the disruptions and discontinuities that often accompany IS innovation might be gained. A deconstructive analysis would consider how texts such as procedural manuals, documentation, design documents and so on, act to impose a dominant meaning on the technology as new or old at that moment. Deconstructive analysis would highlight the unstable, tentative nature of the meanings of an innovation, as IS texts act to recontextualize the new as old (or old as new), thus bringing to the foreground the performative implication of IS texts.

Appendix A provides examples of analytic techniques that have been used in deconstructive analyses in IS and organizational studies. We also refer the reader to Martin (1990a) and Beath \& Orlikowski (1994) for illustrations. Such techniques and methods suggest tangible guidance 
on how deconstruction might be applied in studying the language of IS. However, Jones (2003, p. 41) cautions that deconstruction is more than a method and that its use should take into account its epistemological, ontological, political, and ethical aspects:

We have an encounter with an undecidable situation, where the description of deconstruction as method is necessary but impossible. Hence we might say that we cannot not describe deconstruction as a method, at the same time as we grapple with the dangers of doing so.

As we consider how deconstruction has been or might be applied in IS research, we do so with this broader understanding of deconstruction as both linguistic philosophy and analytic technique, and we accept that there are no simple guidelines for 'doing deconstruction'.

\section{Philosophical critiques of and support for deconstruction}

Not surprisingly, deconstruction has had its critics (see Jones, 2003; Deutscher, 2005; Weitzner, 2007 for discussions). Some critics have complained that deconstruction is applied primarily in ways that are negative toward its object (Jones, 2003), suggesting there is an inappropriate reduction of a philosophical view of language to a critical method. Others consider deconstruction to be a post-modern philosophy (Agger, 1991), as well as poststructuralist. Critics such as Weiss (2000) consider deconstruction as just the latest manifestation of postmodern relativism that will fade away as 'real scientists' continue with their work. Derrida contested such claims, using the term undecidability to focus on the forces in play in language and the determinant oscillation between possibilities, not a relativist indeterminacy. Kilduff (1993, p. 15) argues as well this critique of deconstruction:

... deconstruction is used, not to abolish truth, science, logic and philosophy, but to question how these concepts are present in texts and how they are employed to systematically exclude certain categories of thought and communication.

In contrast to critics, other scholars have highlighted the creativity and intellectual challenges that deconstruction poses. Weitzner (2007) posits that Derrida's concept of undecidability is intrinsically ethical in its call to action, because through texts we are choosing how we construct our worlds. Through this view of Derrida's work, deconstruction can be seen as having a developmental influence on progress (Norris, 2000, p. 84), however wary it is of the idea of progress as a centering and conservative force. By challenging the stabilization and centrality of texts in order to explore the diversity of human possibilities, Derrida's approach presents a call to action but not a prescription for action (Jones, 2003, p. 54):

One can see in Derrida's work, a persistent and radical experience of possibility, based on an opening or openness to the possibilities of an alternative future ... his readings do not simply interpret texts but change them. It is the 'performative' aspect of deconstructive reading ... that recommends deconstruction to a radically transformative politics and ethics.

Some have argued that deconstruction can foster new insights into research topics (Cooper, 1989; Weitzner, 2007), and even highlight the institutional processes that shape research agendas (Ramiller et al, 2008). Agger (1991) posits that deconstruction can help us to open up our own scientific writing to multiple interpretations by readers who actively engage with the text:

Science written from the perspective of deconstruction avoids over-reliance on technical and figural gestures; instead, it continually raises its assumptions to full view and thus invites readers to join or challenge them. (Agger, 1991, pp. 114-115)

In line with these assessments of deconstruction, we suggest that Derrida's approach to language through deconstruction - a close examination and appreciation of the writer's words, their fragile meaning, and the power relations that act to stabilize or destabilize meaning offers possibilities for inspiration in IS research and practice. It could provide opportunities to reflect more deeply and creatively on how we are governed and act through texts, as researchers and as practitioners. As we discuss how deconstruction has been and might be used in qualitative IS research, we consider deconstruction as more than a technique or a method of critique but also as a call to action and accountability for the declarative and performative acts of any and every IS text.

\section{Deconstruction in IS research}

The term deconstruction has been applied loosely in IS research, ranging from philosophical reflections, to analytic techniques, and to a general form of critique. For illustrative purposes, we focus on IS research publications that have explicitly engaged in deconstructive analysis of IS texts. This allows for a deeper examination and consideration of possible applications for deconstruction in IS research. Appendix B summarizes the small body of IS research publications that explicitly reference deconstruction, that employ to some degree the ontological, epistemological, and methodological approaches of formal deconstruction (related to Derrida's work), and that present a deconstructive reading of IS texts. We then consider additional areas in which deconstruction might be employed in language-based IS research.

\section{Illustrations of deconstructive readings of IS texts}

In the publications outlined in Appendix B, IS researchers apply deconstruction as a method of critique to reveal the con-texts that would render different interpretations of an IS text(s). Some analyses draw upon Derrida's approach of rigor and clarity in uncovering metaphors hidden by the apparent objectivity and abstraction in a text, in order to expose excluded possibilities (Norris, 2000, p. 81). 
Others suggest that différance and supplement are evident in logical fallacies, tautologies, ideologies, and law-like assumptions (Martin 1990a; Beath \& Orlikowski, 1994).

Notable works utilizing deconstruction in organizational and IS studies have focused on a single text or related set of texts (cf. Martin, 1990a; Kilduff, 1993; Beath \& Orlikowski, 1994). In IS research, deconstruction has been applied to methodological texts for IS development. The most highly cited of these works is Beath \& Orlikowski's (1994) deconstructive reading of a popular IS development methodology (Information Engineering). Their analysis highlights contradictory ideas about the role of users in IS development and their relationship to IS developers. We consider this study in more depth below. Watson \& Wood-Harper (1996) apply deconstruction to an academic article presenting a framework for examining development methodologies (Lyytinen, 1987), in order to highlight how methodologies limit our understanding of contexts for systems development. They focus on conflicting meanings in IS methodologies and on references to other methods on which a methodology's meaning depends. Truex et al (2000) use deconstruction to consider a-methodological development - a broad consideration of supplemental and oppositional approaches to systems development strategies outlined in methodological texts. In their view, the différance of methodological discourses both suppresses and depends on the supplement of a-methodological development for meaning, thus privileging structure over action, theory over experience, notation over process, and rationalized and controlled design over on-the-fly methods.

Other works illustrate the potential for the deconstructive analysis of important technical and development issues in IT. Davidson et al (2006) examined a Harvard Business Review article promoting web services to explore predictions about the future of IS organizations and IT architecture. By focusing on the dichotomies of differance and supplement in the text, they reveal how the revolutionary and 'new' IT strategy necessarily depends on and evolves from the 'old' and now putatively inadequate architecture, and how the value of human ingenuity is a supplement for the elegance of automation (rather than automation as a supplement to human ingenuity). Coyne (2000) and Robinson et al (1998) consider generally how deconstruction and postmodern perspectives could illuminate the technical and social divide that is pervasive in the discourse of software development.

Examining texts on IS practice, Huysman (2000) examined the use of the phrase 'organizational learning' in the literature to reveal biases and dominant interpretations of what organizational learning entails: an individual action bias, an active agency bias, a purposeful learning bias, and an improvement bias. In a study of how IS designers learned new material, she identified cultural learning as an approach suppressed in the literature, which not only shapes the learning process but also the outcome of learning. Addressing texts within IS, Panteli (2002) examined e-mail exchanges among system users, which revealed how status and hierarchy were evident in clues and cues of language use, syntax and format. This textual analysis suggested that email is a rich medium for conveying social distinctions, in contrast to its usual depiction in theory as a lean medium. (Lee (1994) arrives at a similar conclusion using hermeneutics as the analytic lens).

\section{A deconstructive example}

To consider how deconstruction might be applied to IS texts, we examined Beath \& Orlikowski's (1994) analysis of James Martin's Information Engineering in detail. The authors apply an analytic method drawn from deconstruction to an enduring concern of IS practitioners and researchers: how to effectively include business users in the systems development process. Their work occupies the intersection of industrial and research discourses that Ramiller et al (2008, p. 6) refer to as the ecotone, or the transitional zone between topics of interest to research (esoteric topics) and to industry (excluded topics). In doing so, the authors subject a practitioner text - the volumes of the information engineering methodology of James Martin $(1989,1990 b, c)$ - to a deconstructive analysis that critiques the methodology's ambivalence and contradictions toward user involvement.

To supplement and justify their use of deconstruction, the authors devote several pages to explain deconstruction and to draw specific analytic techniques from a previous deconstructive text by Joanne Martin (1990a). Their description of their study both differs from more familiar qualitative methods, such as content analysis, yet defers to these methods by listing the percentages of the text and chapters extracted for review, and the number of pages and passages subjected to the deconstructive analysis. The authors explain how their varied interpretations were reconciled through individual and joint analysis of passages, resulting in two major oppositional motifs around which they re-center the original text: 'the ideology of user involvement' and 'the false dichotomy between users and IS analysts' (p. 347).

As Derrida observed, the overturning of the différance and supplement in the original text is a violent overturning of implicit oppositions. A new text emerges from the old, as contradictions are exposed (Beath \& Orlikowski, 1994, p. 373). Re-centering of the original text's statements about users and developers is accomplished by organizing selected passages from the original text around the ideological themes of user involvement and analyst/developer dichotomies. The authors use analytic techniques adapted from Joanne Martin (1990a) and explicated in a supplemental table (Beath \& Orlikowski, 1994, pp. 356-357) to expose the assumed hierarchy of analyst/developer and user. Additional tables of selected phrases further deconstruct then reconstruct portions of the original text around the researchers' new 
dichotomy of 'unidentified' and 'identified' participants (Tables 3 and 4, pp. 362-365).

Beath \& Orlikowski (1994, p. 373) follow Kilduff's (1993) assertion that deconstruction, which occurs within a text, carries implications for the world outside the text:

Deconstruction also leads us to consider how the contradictions and ideological elements in texts mirror those in the world ... Texts such as systems development methodologies thus are likely derivative of their institutional contexts ... in systems development, the interdependence between users and analysis is often rendered as a relationship of dominance/dependence. The very notion of 'user involvement' portrays IS as naturally in charge and having the authority to decree the participation of users in the development of their own work support systems. The systems development context thus enacted is one in which some people are designated technical experts and others are designated consumers of technical expertise.

Although these assertions focus on text as a reflection of the world, the authors suggest that texts also act in and upon the world, and that confronting the contradictions within the discourses on systems development approaches inscribed within methodological texts is a necessary step for researchers to inform and practitioners to establish more effective user/analyst relationships.

One way to assess contributions of this deconstructive analysis is to consider how Beath \& Orlikowski's (1994) text has been intertextually connected with other research texts in the IS research field. We found over 50 citations to Beath \& Orlikowski (1994) in the Web of Science electronic citation index as of December, 2009. (Scholar.google.com produced 199 citations to this paper on 6 September 2010.) This text has been referenced in studies focused on topics of interest both to IS practitioners and researchers, such as negotiating requirements, systems acceptance, user participation, project management, and systems development methods, as well as esoteric topics (Ramiller et al, 2008) such as discourse analysis and research methods. (This analysis is available from the second author via email request.) It has served as a supplement, through various textual marks such as references and citations, in diverse methodological studies from interpretive field studies (cf. Lin \& Silva, 2005) to positivist surveys (cf. Maruping et al, 2009). Thus, Beath \& Orlikowski's (1994) text has, in a manner of speaking, become the object of numerous deconstructive readings - a possibility that the authors acknowledged in their own text - that extend its insights in new and possibly unexpected ways.

\section{Reconsidering possibilities for deconstructive readings of IS texts}

This small body of IS publications illustrates possible uses of deconstruction in IS research. These include the examination of contradictions and suppressed concepts and topics in system development approaches and methodologies. Here, we suggest that deconstruction
Table 1 Examples of IS texts

\begin{tabular}{|c|c|}
\hline Types of IS texts & Examples \\
\hline Prescriptive texts & $\begin{array}{l}\text { Systems development methodologies } \\
\text { Commentaries on IS practices } \\
\text { Predictions of future technology trends } \\
\text { Practitioner-focused reports of scholarly } \\
\text { research } \\
\text { Standards documents }\end{array}$ \\
\hline Descriptive texts & $\begin{array}{l}\text { System narratives } \\
\text { User procedural manuals } \\
\text { Technical manuals }\end{array}$ \\
\hline Developmental texts & $\begin{array}{l}\text { Requirements documents } \\
\text { System specifications } \\
\text { Program specifications } \\
\text { Diagrams and drawings used in analysis }\end{array}$ \\
\hline IS/IT artifacts as text & $\begin{array}{l}\text { Web-based information systems } \\
\text { Social networking systems } \\
\text { System interfaces } \\
\text { Program logic }\end{array}$ \\
\hline IS educational texts & $\begin{array}{l}\text { Textbooks } \\
\text { Pedagogical case studies } \\
\text { Power point presentations used in class }\end{array}$ \\
\hline IS research texts & $\begin{array}{l}\text { Scholarly journal articles } \\
\text { Scholarly books } \\
\text { Conference papers } \\
\text { Paper presentations }\end{array}$ \\
\hline
\end{tabular}

might be employed in language-based analysis of a much wider variety of IS texts, including prescriptive, descriptive, and developmental IS texts, and even for IS/IT artifacts viewed as 'texts' in the broad sense of this term. We also highlight two types of texts of concern primarily to IS researchers: educational and research texts. Table 1 summarizes these genres of IS text, and the following discussion summarizes our thoughts on why deconstructive approaches might be valuable to gain fresh and creative insights on long-standing IS issues.

Prescriptive IS texts Commentaries about IS technologies, uses, and practices present idealized and apparently stabilized texts to guide IS practice. These prescriptions are often justified and supported by claims to technical superiority and functioning, which are supplemented through references to other texts such as white papers, research studies, and expert opinions that support interpretations and claims. Texts highlighting social and political influences that could render the prescriptions open to critique are typically absent. As one example, the proclaimed use of web services to automate and replace human intervention in the operation of interorganizational IS (Hagel \& Brown, 2001) can be shown 
through a deconstructive reading to depend upon the same human activities to define the 'language' of web services standards, which this prescriptive text suggests be replaced (Davidson et al, 2006). Within the genre of prescriptive texts, the meaning of an IT innovation is not fixed but open to alternative interpretations. Interestingly, the same innovation concept (web services) is recontextualized in a different prescriptive text (McAfee, 2005), through references to other supplements (an organizational case study). McAfee's (2005) questioning of assumptions about the inevitability and ease of developing web services resonates with insights generated through deconstruction about the 'naturalness' of innovation. The deconstructive reading has a more critical edge, however, to emphasize various tensions of différance and supplement in IT innovation.

If we assume that texts act in the world (Kilduff, 1993; Beath \& Orlikowski, 1994), the performative implications of prescriptive texts warrant deconstructive scrutiny. Practitioner-oriented texts promoting business process reengineering, for instance, provided a direction for IT-enabled organizational change in the 1990s. The title of Hammer's well-known article, 'Don't Automate: Obliterate' (Hammer, 1990), was a call-to-arms in justifying and empowering IS engineers to intervene in organizational processes. Projects focused on the obliteration of business process complexity at times simplified important nuances and resulted in dissatisfied customers and producers. Organizational members discovered that business processes were in-fact complex and nuanced, and business process diagrams (as texts) failed to capture these important nuances. The complexities and nuances of business process are suppressed to some degree in any text, of course. Our point is that any prescriptive text related to IS innovation, development and use typically presents practitioners with a singular and simplified interpretation of business processes, suggesting that business process complexity is unnecessary - a supplement. Through deconstructive play, the oppositional forces of the differance of simplicity and the supplement of complexity might be surfaced and explored explicitly, in order to promote recognition and debate about alternative viewpoints and designs.

Descriptive IS texts Many types of IS texts support and constrain organizational interpretations of an IS in practice. These include manuals, documents, printed reports and so on. Such texts attempt to stabilize a dominant interpretation of an IS, acting as the supplement to the technology artifact. Beyond simply describing a given software system, however, supporting texts are performative, directing the users' attention to particular uses for the system, for example, presenting recommendations on how and why to use system features. These supplemental texts, by supporting a dominant interpretation of the system, suppress other possibilities for systems use, though they are seldom effective in doing so unconditionally. The well-known phenomena of systems users finding unconventional ways to appropriate technological features illustrates both the presence of deferred possibilities and the equivocal, ephemeral nature of technology use practices. In this regard, deconstruction might complement practice-lens approaches, which highlight the situated and emergent nature of IT use through empirical observational methods (Orlikowski, 2000). Deconstructive play in the reading of IS texts might surface possibilities for unconventional (even unimagined) technology uses - some encouraged, some discouraged by technology designers and implementers - in ways that conventional empirical analysis of use practices might not. For example, when considering the différance of 'appropriate use' of an IS, invoking of the supplement of various 'inappropriate uses' could be brought to the forefront, highlighting the ways in which descriptive texts act to stabilize or destabilize legitimated meanings attributed to IS in a given context.

Developmental IS texts IS development and implementation processes rely on many IS texts, suggesting these texts and the languages they employ might be analyzed using deconstruction. For example, if we deconstructed a system specification document and the 'requirements' specified within it, non-requirements (the absented list of requirements) might be evident. If surfaced through deconstructive play, would 'non-requirements' overturn and destabilize the dominant interpretation of requirements? Deconstruction could raise the question of how and why particular texts come to dominate requirements processes in the first place, while others do not. What are the texts (such as meeting minutes, white-board sketches, and system documents) that are absent and suppressed, but nonetheless supplement the dominant interpretation of requirements within the specification document? Examining the use of marks and signs, such as the use of numbers in the margins to rank order requirements, can highlight how these supplements impose a certain and arbitrary priority on each requirement. The term 'requirements' per se adds force to what may be recast through deconstructive play as a 'wish list'.

Our point is not to suggest that requirements definition processes be rendered even more confusing or contentious through deconstruction. Instead, we suggest that deconstruction might provide novel insights on the well-known problems of requirements definition, such as conflicts over organizational power and politics, difficulties with knowledge sharing and the mutual coordination among requirements participants, or ongoing technical and organizational change. Deconstruction highlights the ephemeral, situated, and fragile nature of requirements within the texts on which they are inscribed, and highlights both the accomplishment and the instability of specifications. In doing so, deconstruction of developmental IS texts might be seen as a form of improvisation (Orlikowski, 1996) and a nuanced supplement to critical 
theory approaches that investigate power relationships in systems development.

IS/IT artifacts IS act as texts to present particular representations of organizational routines and practices. Database structures, user interfaces, and software algorithms are constructed to enable certain practices, but in doing so, they disable or suppress other designs. We suggest that even IS and technologies could be the subject of deconstructive analysis, although the analytic techniques outlined in Appendix A may be insufficient to address the stylized, formalized languages on which IT artifacts are built. IS interfaces and logic (screens, databases, reports, and software) could be analyzed to expose dominated and suppressed possibilities upon which every IS rests. Deconstruction could focus on design elements that are present as supplements, different from and deferred to the dominant design, yet potentially emergent.

As one example, a software prototype could be seen as an IS text where a specific system future is being written for the organization. Any version of a prototype rests upon various other suppressed possibilities for what the design might be. For example, the layout of a software screen may suggest and reinforce particular patterns of authority and authorization in an organizational process. Not only might the prototype itself be deconstructed to investigate other possible designs, but the prototyping process per se can be inherently deconstructive, if the drive toward a singular and convergent design is resisted (for a time). Instead of moving quickly toward an agreeable and agreed-to prototype, through iterations designers can produce a range of designs that may expose and challenge users' and designers' understanding of current practices and business processes to suggest new possibilities (Chiasson \& Dexter, 2001).

Two additional areas of application of deconstruction are applicable to the work of IS researchers as scholars. IS education and pedagogy texts might incorporate deconstructive exercises for IS students. This educational approach would differ from what is often called critical thinking by directing students' attention to unrealized, absent and suppressed possibilities and approaches to system design. A deconstructive view of systems analysis could also help students recognize that systems development is necessarily the construction of a singular, incomplete, and unstable system text - a form of postmodern system development (Robinson et al, 1998). Systems designs perceived as incomplete and open to change could be recast as a design goal, not a design limitation. Interestingly, the modern systems development environments of Web 2.0 and 'app' development platforms rely on ideas of 'plug and play' and 'mashup' functionality, which (it has been argued) can be easily re-contextualized. Both these systems design possibilities and claims of ease of use could be the subject of students' deconstructive analyses.
Finally, IS research publications, especially commentaries on IS research containing normative statements about the field and its future practices, could be subjected to deconstructive analysis. Ramiller et al (2008, p. 16) recommend deconstruction as an analytic strategy to investigate the institutional ecology of IS research, in order to better understand how and why our research community comes to research the topics that we do, commenting, 'deconstruction can illuminate situations where academic work, despite the conventional veneer of cool and impartial scientific reasoning, can become captive to larger ideological movements'. It has been suggested to us that deconstruction shares some analytic approaches with academic genres such as a literature review in an academic paper (i.e., intertextuality). Academic writers acknowledge the intertextuality of ideas and concepts through citations to other publications, carefully examining terms and constructs to explore their meanings, and highlight missing insights in previous research to be addressed in the current manuscript. The author does so mainly to create a rhetorical argument that focuses the reader (and the reviewers) on the intended contributions of the current text. In contrast, deconstruction does not produce broad conclusions about literature in order to motivate specific future research. Instead it resists logocentric interpretations and attempts to overturn them, by challenging the differrance and supplement of language used in an area of research inquiry.

For example, we suggest that the concept of research relevance in the IS field has gone through various deconstructive efforts without being called deconstruction. Questions about what constitutes relevant research, the consumption of relevant research, open or restricted diversity, and so on demonstrate oppositional logics that raise opportunities for further discussion about meaningful IS research directions. We could argue, for instance, that abstracting IS findings from their context in the quest for generalization is a loss of specific relevance, in the hopes of being a source of insight into future settings and practices, and that the differance of generalizing into the future necessarily situates knowledge of the specific context as supplement. We might consider as well the supplement of relevance - irrelevance - and whether the IS field could also tolerate an apparently irrelevant (and perhaps irreverent) approach to research such as deconstruction. We turn next to this question as we discuss reception of deconstruction in the IS field.

\section{Is deconstruction practical in IS research?}

When we read IS texts, as practitioners or as researchers, we are typically concerned with what the authors intended to say, whether what they say is correct, or accurate, or useful, and whether we agree or disagree. We expect 'takeaway' prescriptions - the very logocentric differance that deconstruction aims to overturn. Is an esoteric analytic approach such as deconstruction practical in the IS field? To explore this question, we 
consider the différance of practical and conventional research and the supplement of unconventional and arguably impractical approaches, which may nonetheless (we suggest) be of value to the IS field. In doing so, we highlight challenges to wider acceptance of deconstruction in the IS field. Some challenges arise generally from differences in the epistemology of the social sciences and of the humanities (Zald, 1993). Others are grounded in the contexts of the IS field and its research.

\section{The différance of practicality and impracticality}

The commonly held expectation that IS research must have practical applications - that is, implications for practice must be drawn forth and centered in our IS texts likely contributes to the IS field's disregard for deconstruction as a research approach. When evaluated within the social science and engineering paradigms that dominate organizational studies (Zald, 1993) and IS, deconstruction appears to be impractical. Displaying an appreciation for a text while subjecting it to deconstructive analysis requires the analyst to exhibit considerable rhetorical skill to avoid reducing the analysis to pure critique. Not surprisingly, deconstructive analyses are often viewed by readers and by the authors of the deconstructed texts as purposefully negative, irrelevant and irreverent, and thus not practical. Moreover, deconstruction offers no straightforward prescriptions and has been accused of relativism (Weiss, 2000). We have argued that Derrida's philosophy is a call to action, but we noted that deconstruction (in contrast to critical theory) does not provide a prescription for action. Instead, deconstruction destabilizes dominant interpretations of a text to surface alternatives and calls on the reader to decide what actions to take.

Such criticisms of deconstruction are not unique to the IS field but they are particularly powerful, given the field's often-proclaimed goals of being specifically and explicitly 'relevant to practice' (cf., Benbasat \& Zmud, 1999). In this regard, Zald (1993) argues against an exclusive focus on solving the problems of practitioners, which tends to dominate practice-based fields (such as IS), and suggests that scholars in these fields embrace more fully the philosophies and methods of the humanities, including deconstruction. In this view, enlightened commentary and reflection are the supplement, different from and deferred to practical advice and techniques, yet nonetheless potential intellectual contributions that scholars, removed from the pressures of practice, may make to a field of practice.

Overturning the différance of practicality and supplement of (assumed) impracticality, we suggest that by (sometimes) stepping back from the specific problems of practice, IS researchers might use deconstruction to generate novel insights on IS phenomena of interest unusual, original, exceptional, even quirky perspectives that contribute to creativity in the field. The publications summarized in Appendix B are examples of putatively impractical works of deconstruction, which nonetheless have important implications for the practice of IS development. Applying deconstruction to descriptive and developmental documents, and particularly to IS artifacts, will be even more experimental and risky. Doing so would likely require new analytic techniques to deconstruct the stylized languages (including programming languages) and design models of IS artifacts. Selecting texts and artifacts to deconstruct is likely to be frustrating with uncertain outcomes. However, breakthrough innovations in design often requires the overturning of taken-for-granted assumptions, and deconstruction offers one approach to help do so.

Using Derrida's terminology, whether deconstruction is practical or impractical in the IS field is undecidable. The answer is not implicit in this (or other) texts. The meaning that deconstruction might have for IS research vacillates between these oppositional poles, as the instances in which works of deconstruction have appeared in IS journals illustrate. This does not mean that decisions about its practicality are not imposed by the IS researchers who choose (or choose not) to draw on deconstruction and by the journal editors and reviewers who evaluate works of deconstruction. Instead, undecidability is a call for action, for deciding whether (or not) to sanction such unconventional research in the IS field.

\section{The différance of conventional and unconventional research approaches}

Deconstruction is unconventional compared with more conventional qualitative methods. This helps explain why it has found limited application in IS research, as well as other practice-based fields, even among qualitative researchers interested in language-based methods. How it would fit with the editorial policies of conventional IS journals is problematic. Deconstruction is difficult to classify as a research approach: it is not a critique, or a method, or an analysis in the straightforward sense. Deconstruction is a radically interpretive approach to language, and deconstructive analysis is both an appreciative and a critical reading of a text that attempts to seek out its structures, and to dismantle them, so as to discern alternative understandings (Derrida, 1985; Jones 2003; Royle, 2003). The philosophical assumptions are that any interpretation is tentative and open to revision. Such analysis cannot produce the outward signals of validity required of quantitative methods and often expected of qualitative methods as well. For example, attempting to legitimate a deconstructive analysis through inter-rater reliability codes or counts of occurrences of phrases or concepts is antithetical to the epistemology of deconstruction.

Another challenge for this unconventional approach is that the concepts and terminology of deconstruction are opaque, as even admirers of Derrida have noted (cf., Deutscher, 2005). Statistical analytic techniques similarly depend on arcane terminology and (to many readers) are 
complex and opaque, but these techniques are widely taught to IS academics and are generally accepted in IS journals with limited explanation of the techniques. That is, the author does not typically need to explain the network of assumptions a statistical technique draws on but instead focuses on how the technique was employed. As an example, the supplement of a ' $P$-value' contained in parenthesis $(P<0.05)$ requires no explanation, just an assigned value. In contrast, the philosophical and analytic methods of deconstruction are familiar to a limited audience of IS researchers - a problem we hope this paper may help address in the IS research field. Thus, basic tenets must be reviewed and explained anew in each research publication as well as supplemented by references to other interpretations (as we have done here).

Given that deconstruction is an unconventional (and unfamiliar) approach in IS research, the authors of deconstructive analysis would have to argue persuasively on its behalf to reviewers and readers. Whether comparable insights might be produced by more conventional and more familiar qualitative methods is a question that journal editors and reviewers are likely to raise. We noted earlier several instances in which similar insights might be (or have been) gleaned through more conventional qualitative methods, such as field observation. However, we also argued that deconstruction might provide 'a new take' that complements and even contradicts such work, by putting into play the view of IS texts as reified reflections of practice. Deconstruction also brings to the foreground the performative nature of any IS text and its deconstructive revisions. It is the exploration of the space in-between these texts and the power mediated through them that renders deconstruction uniquely valuable, beyond interpretative, critical theoretical, structuralist and other post-structuralist approaches.

Gaining broader interest in and acceptance of such unconventional work in the IS field will be challenging. For IS researchers intrigued by deconstruction, we would caution there are no easy prescriptions and there are significant challenges. However, there is also reason for optimism. Analyses applying deconstruction have in fact been published in well-respected IS and organizational journals. Our examination of Beath \& Orlikowski's (1994) publication suggests that applying this analytic approach to topics of practical significance and generating novel insights in a compelling narrative can be persuasive and influential. The authors' use of deconstruction gains meaning by pointing to more familiar and accepted qualitative methods like content analysis, but at the same time accomplishes its own unique task. While this paper and Kilduff's (1993) deconstruct influential practitioner texts, Joanne Martin (1990a) provides a playful deconstruction of a conversational snippet taken from a public event, generating provocative perspectives on tensions surrounding gender equality and work-family balance in corporate life. That is, the authority or fame of the text deconstructed is not the sole arbiter of the value of the deconstruction; even the deconstruction of everyday texts of interactions may be revealing. In this essay, we highlighted various genres of IS texts - from the mundane to the famous - that might profitably become the objects of deconstructive analysis.

Overturning the différance of conventional qualitative research approaches to admit possible contributions of unconventional approaches such as deconstruction depends on the actions that IS scholars take in their production and consumption of texts. Special issues of journals, edited books, or conference mini-tracks could be used to foster experimentation with deconstruction in IS (perhaps within a broad spectrum of languagebased approaches to IS research). In such forums, the work of explicating key concepts might be done in supplemental materials such as introductory chapters, and a cadre of informed reviewers and an appreciative constituency might develop as well. Such was the case with the acceptance of qualitative field methods in the IS field in the late-20th century. We anticipate a similar course of development for philosophical and methodological approaches such as deconstruction is possible as well.

\section{Conclusions}

Deconstruction is a novel (to the IS field) languagebased approach to analyzing the many texts through which IS artifacts, practices, policies, and outcomes are realized. We have argued that the philosophy and analytic methods of deconstruction might inspire creative and innovative insights for IS research and practice as we look deeply into the many IS texts that specify idealized future systems, architectures, and development methods. Although such analysis will often have a strong critical flavor, inspiration might come not from creating new prescriptions but from recognizing and articulating the inability of any prescription, however tight and elegant, to withstand a rigorous deconstruction. Deconstruction allows us to view texts as political and rhetorical paths to the future, which demand a healthy appreciation, suspicion and de-centering to reveal absent and suppressed possibilities. The foundation of our future is in our texts, what they leave in and what they leave out. Deconstruction might help us envision new possibilities through the study of various types of IS texts; the oppositions between and within the texts might be revealed, producing a more balanced and richer consideration of IS futures. To this end, we have argued that deconstruction allows what Alvesson \& Karreman (2000) recommend - appreciating the texts we produce and consume as IS researchers, but also unburdening texts from such high expectations of what they can accomplish. By accepting them as incomplete and unstable visions of the future, we can re-examine and re-consider them to generate new possibilities for the future. 


\section{About the authors}

Mike Chiasson is a Professor at the Department of Management Science at Lancaster University. His research examines how the social context affects IS development and implementation, particularly in service-sector and professional organizations. He has published a number of essays examining the relationships between research methodology and philosophy of science in information systems research. Dr. Chiasson serves as Programme Director for the MSc in Information Technology, Management and Organisational Change (ITMOC) and has served as AIM Innovation Fellow (2007-2009). He has served as Associate Editor for MIS Quarterly and Information Systems Journal.

\section{References}

AGGER B (1991) Critical theory, poststructuralism, postmodernism: their sociological relevance. Annual Review of Sociology 17, 105-131.

ALVESSON M and KARREMAN D (2000) Taking the linguistic turn in organizational research. The Journal of Applied Behavioral Science 36(2), 136-158.

BEATH C and ORLIKOWSKI W (1994) The contradictory structure of systems development methodologies: deconstructing the IS-user relationship in information engineering. Information Systems Research 5(4), 350-377.

BENBASAT I and ZMUD R (1999) Empirical research in information systems: the practice of relevance. Management Information Systems Quarterly 23(1), 3-16.

CALÁS M and SMIRCICH L (1991) Voicing seduction to silence leadership. Organization Studies 12(4), 567-601.

CHIA R (1994) The concept of decision: a deconstructive analysis. Journal of Management Studies 31(6), 781-806.

CHIASSON M and DEXTER A (2001) System development conflict during the use of an information systems prototyping method of action research: implications for practice and research. Information Technology and People 14(1), 91-108.

COOPER R (1989) Modernism, post modernism and organizational analysis 4: the contributions of Jacques Derrida. Organization Studies 10(4), 479-502.

COYNE R (2000) Designing Information Technology in the Postmodern Age. MIT Press, Cambridge, MA.

CROTTY M (1998) The Foundations of Social Research. Sage, Thousand Oaks, CA.

DAVIDSON D, CHIASSON M and RUIKAR S (2006) Taking the people out of the network: a deconstruction of 'your next IT strategy'. In Social Inclusions: Societal and Organizational Implications for Information Systems (Trauth E, Howcroft D, Butler T, Fitzgerald B and Degross J, Eds), pp 317-332, Springer, New York.

DERRIDA J (1978) Of Grammatology Trans. Spivak GC, John Hopkins University Press, Baltimore and London.

DERRIDA J (1981) Positions. University of Chicago Press, Chicago.

DERRIDA J (1982) Différance: Margins of Philosophy. University of Chicago Press, Chicago \& London.

DERRIDA J (1985) Letter to a Japanese friend. In Derrida and Différance (WoOd D and Bernasconi R, Eds), p 3, Parousia, Warwick.

DerridA J (2002) Positions, 2nd edn Continuum, London.

DEUTSCHER P (2005) How to Read Derrida. W.W. Norton and Company, New York.

FAIRCLOUGH N (2003) Analysing Discourse: Textual Analysis for Social Research. Taylor \& Francis, London.

FEenberG A (2002) Transforming Technology: A Critical Theory Revisited. Oxford University Press, Oxford.

Foucault M (1990) The History of Sexuality: An Introduction, Vol. 1. Vintage Books, New York.

Foucault M (1995) Discipline and Punish: The Birth of the Prison. Vintage Books, New York.

HAGEL J and BROWN JS (2001) Your next IT strategy. Harvard Business Review 105-113.
Elizabeth Davidson chairs the Department of Information Technology Management in the Shidler College of Business at the University of Hawaii. Her research investigates the organizational and societal implications of information technologies using qualitative research and discourse analysis methods. Much of her research has addressed change associated with diffusion and use of health information technologies. She has served as Associate Editor for MIS Quarterly and the European Journal of Information Systems and Senior Editor for Information and Organization. Her publications have appeared in these and other IS journal outlets.

HAMMER M (1990) Reengineering work: don't automate, obliterate. Harvard Business Review 68(4), 104-112.

HARLAND R (1987) Superstructuralism: The Philosophy of Structuralism and Post-structuralism. Methuen, London.

HeraCleOUS L (2006) Discourse, Interpretation, Organization. Cambridge University Press, Cambridge.

HERACLEOUS L and BARRETT M (2001) Organizational change is discourse: communicative actions \& deep structures in the context of IT implementation. Academy of Management Journal 44(4), 755-778.

HIRSCHHEIM R, KLEIN H and LYYTINEN K (1996) Exploring the intellectual structures of information systems development. Accounting Management and Information Technologies 6(1/2), 1-64.

HIRSCHHEIM R and KLEIN H (1994) Realizing emancipatory principles in information systems development: the case for ETHICS. MIS Quarterly 18(1), 83-109.

HUYSMAN M (2000) Rethinking organizational learning: analyzing learning processes of information systems designers. Accounting, Management and Information Technologies 10(2), 81-99.

JONES C (2003) Jacques Derrida. In Organization Theory and Postmodern Thought (LINSTEAD S, Ed.), pp 34-69, GBR, Sage Publications, London.

KILDUFF M (1993) Deconstructing organizations. Academy of Management Review 18(1), 13-31.

LEE A (1994) Electronic mail as a medium for rich communication: an empirical investigation using hermeneutic interpretation. MIS Quarterly 18(2), 143-157.

LIN A and SILVA L (2005) The social and political construction of technological frames. European Journal of Information Systems. 14(1), 49-59.

LYYTINEN K (1987) A taxonomic perspective of information systems development: theoretic constructs and recommendations. In Critical Issues in Information Systems Research (BOLAND RJ and HIERSHHEIM R, Eds), pp 3-41, John Wiley and Sons, Chichester.

LYYTINEN K and HIRSCHHEIM R (1988) Information systems as rational discourse: an application of Habermas's theory of communicative action. Scandinavian Journal of Management 4(1/2), 19-30.

MARTIN J (1989) Information Engineering, Book I: Introduction. PrenticeHall, Englewood Cliffs, NJ.

MARTIN J (1990a) Deconstructing organizational taboos: the suppression of gender conflict in organizations. Organization Science 1(4), 339-359.

MARTIN J (1990b) Information Engineering, Book II: Planning and Analysis. Prentice-Hall, Englewood Cliffs, NJ.

MARTIN J (1990c) Information Engineering. Book III: Design and Construction. Prentice-Hall, Englewood Cliffs, NJ.

MARUPING LM, VeNKATESH $V$ and AGARWAL R (2009) A control theory perspective on Agile methodology use and changing user requirements. Information Systems Research 20(3), 377-399.

MCAFEE A (2005) Will web services really transform collaboration? Sloan Management Review 46(2), 78-84.

MILNER A (1991) Contemporary Cultural Theory: An Introduction. Allen \& Unwin, Sydney. 
NORRIS C (1991) Deconstruction: Theory and practice. Routledge, London.

NORRIS C (2000) Deconstruction and the 'Unfinished Project of Modernity'. Routledge, New York.

NGWENYAMA O and LEE A (1997) Communication richness in electronic mail: critical social theory and the contextuality of meaning. Management Information Systems Quarterly 21(2), 145-167.

ORLIKOWSKI W (1996) Improvising organizational transformation over time: a situated change perspective. Information Systems Research 7(1), 63-92.

ORLIKOWSKI W (2000) Using technology and constituting structures: a practice lens for studying technology in organizations. Organization Science 11(4), 404-428.

PANTELI N (2002) Richness, power cues and email text. Information and Management 40(2), 75-86.

PHILLIPS N and HARDY C (2002) Discourse Analysis: Investigating Processes of Social Construction. Sage Publications, Thousand Oaks, CA.

PRASAD P (2005) Crafting Qualitative Research: Working in the Postpositivist Traditions. ME Sharpe, Amonk, NY.

RAMILLER N, SWANSON EB and WANG P (2008) Research directions in information systems: toward an institutional ecology. Journal of the Association for Information Systems 9(1), 1-22.

RoBinson H, HaLl P, HOVEnden F and Rachel J (1998) Postmodern software development. The Computer Journal 41(6), 363-775.

ROYLE R (2003) Jacques Derrida. Routledge, London.
SWANSON EB and RAMILLER N (1997) The organizing vision in information systems innovation. Organization Science 8(5), 458-474.

TRUEX D, BASKERVILLE R and TRAVIS J (2000) A-methodological systems development: the deferred meaning of systems development methods. Accounting, Management and Information Technology 10, 53-79.

URQUHART C (1999) Themes in early requirements gathering: the case of the analyst, the client and the student assistance scheme. Information, Technology and People 12(1), 44-70.

URQUHART C (2001) Analysts and clients in organisational contexts: a conversational perspective. Journal of Strategic Information Systems 10, 243-262.

WATSON H and WOOD-HARPER T (1996) Deconstruction contexts in interpreting methodology. Journal of Information Technology 11, 59-70.

WEISS R (2000) Taking science out of organization science: how would postmodernism reconstruct the analysis of organizations. Organization Science 11(6), 709-733.

WEITZNER D (2007) Deconstruction revisited: implication of theory over methodology. Journal of Management Inquiry 16(1), 43-55.

WILLIS R and ChIASSON M (2007) Do the ends justify the means? A Gramscian critique of the processes of consent during an ERP implementation. Information Technology \& People 20(3), 212-234.

ZALD M (1993) Organization studies as a scientific and humanistic enterprise: toward a reconceptualization of the foundations of the field. Organization Science 4(4), 513-528. 


\title{
Appendix A
}

Table A1 Examples of analytic techniques for deconstructive readings of a text

\begin{abstract}
Analytic Strategy: Dismantling a dichotomy
Deconstruction focuses analytic attention on différance and supplement, which may be evident as oppositional pairs or dichotomies. Davidson et al (2006) highlight the différance and supplement of old and new when discussing web services, pointing out the revolutionary 'new' architecture depends on and grows from the existing, 'old' architecture. Similarly, the 'freedom' of the new architecture relies on the 'constraints' of firmly established and enforced standards and policies.
\end{abstract}

Analytic Strategy: Attending to disruptions and contradictions

Deconstruction focuses attention on points at which the dominant meaning in a text appears to break down. Analyzing the text statement, 'Taking the people out of the network, the architecture will enable connections between applications - both within and across enterprises - to be managed automatically' (Hagel \& Brown, 2001, p. 109). Davidson et al (2006) comment that people create and operate 'the architecture' and thus cannot be taken out of it.

Analytic Strategy: Scrutinizing naturalness claims or arguments

The dominant meaning of a text emerges in part from claims of naturalness by suppressing consideration of 'unnatural' approaches. Davidson et al (2006) note the naturalness claims in the statement, 'Shared meaning will naturally increase as the use of the web services architecture expands' (Hagel \& Brown, 2001, p. 113). 'Shared meaning' is synonymous with standardized definitions. These standards, and any meaning associated with them, emerge through an 'unnatural', concerted and often contentious debate and negotiations among people (vendors, users).

Analytic Strategy: Examining silences

A text speaks not only through what it says, but what it leaves unsaid, because the explicit relies on the tacit as supplement for meaning. Davidson et al (2006) attend to the text's silence about the information technology workers who create IT capabilities, particularly IT professionals, who are referred to only as burdens to be shed, as the deconstructed text promotes the benefits of the technical architecture. Thus, human ability differs from and defers to the elegance of automation by being removed and made invisible.

\section{Analytic Strategy: Focusing on marginalized elements}

Marginalization through footnotes, parenthesis, sidebars and so on, convey the différance of the text and the supplement of its subtexts. For example, a point in the text cannot be understood without the supplement of the footnote. Davidson et al (2006), draw attention to how the implications for the IT department of this new strategy are relegated to a sidebar, in which only the CIO's role is considered.

Analytic Strategy: Interpreting metaphors for multiple meanings

Metaphors are tropes that suggest similarities in relational structures between concepts; although they foreground some possible meanings, the push others to the background and they are open to multiple interpretations. Davidson et al (2006), highlight the contradiction of the metaphor of integrative systems as 'restrictive enterprise silos' (p. 106).

Analytic Strategy: Analyzing double entendres

Similar to metaphors, a double entendre suggests conflict and contestation between ideas, and in the oppositional pairs of différance and supplement. Davidson et al (2006) suggest that the statement about Web Services, 'In the process, many companies will find themselves turned inside out, with their formally well-guarded core capabilities visible and accessible to all.' (p. 113) implies that turning the inside out is both 'desirable' and threatening. (The undecidability of inside and outside was of particular interest to Derrida (Deutscher, 2005)).

These are examples of analytic techniques used by Davidson et al (2006) in their deconstructive reading of the text, 'Your next IT strategy' (Hagel \& Brown, 2001). These techniques were adopted from Martin (1990a, p. 355, Figure 1) and Beath \& Orlikowski (1994, p. 356, Table 2). The reader can find other examples and detailed explanations in these publications. 


\section{Appendix B}

Table B1 Exemplary IS research publication employing deconstruction

\begin{tabular}{ll}
\hline Author & IS Text examined \\
\hline Beath \& Orlikowski (1994) & Systems development methodology \\
Coyne (2000) & General discourse of systems design \\
Davidson et al (2006) & $\begin{array}{l}\text { Harvard Business Review article on web } \\
\text { services }\end{array}$
\end{tabular}

Huysman (2000)

Literature on organizational learning related to IS designers' routines Key insights Exposes contradictions and ideological elements in systems development that privilege technical developers' role in methodology over users

Reviews Derrida's work on deconstruction and post-modern approaches that inform philosophy of systems design

Reveals dichotomies in arguments promoting web services as a revolutionary new IT strategy, which also suggest privileging automation over human control in IS architecture

Reveals biases in the literature on organizational learning that obscure other forms of learning evident in practice, that is, cultural, mutual, unintended learning, which are not directed towards instrumental improvements

Panteli (2002)

Text in email exchanges

A close examination of email texts reveals cues to social status and hierarchy, suggesting email is a rich medium rather than a lean one as suggested by theory

Robinson et al (1998)

Truex et al (2000)

Watson \& Wood-Harper (1996)
General discourse of systems design

General discourse on methodologies

Academic paper on IS development methodology
Critiques the technical/social divide and the privileging of the technical over the social in discourse on the 'crisis in software development'.

Exposes a-methodological systems development as a suppressed alternative to methodological development, by examining dichotomies in the discourse

Identifies conflicts within methodologies, references to other methods as self-description, asymmetrical oppositions, marginalization of context by methodologies 